\title{
Three-dimensional influence zone of new tunnel excavation crossing underneath existing tunnel
}

\author{
Thayanan Boonyarak ${ }^{\text {i) }}$ and Charles W. W. Ng ii)
}

\begin{abstract}
i) Chief of engineering division, Seafco public company limited, 144 Prayasuren Road, Klongsamwah, Bangkok, Thailand. (Former PhD candidate at the Hong Kong University of Science and Technology)

ii) Chair professor, Department of Civil and Environmental Engineering,

The Hong Kong University of Science and Technology, Clear Water Bay Road, Kowloon, Hong Kong.
\end{abstract}

\begin{abstract}
Due to an increasing number of constructed tunnels in urban areas, excavation of a new tunnel may cause damage to adjacent existing tunnels. In order to assess damage on the existing tunnel, it is important to improve our understanding of the influence zone due to new tunnel excavation. The influence zone may include the location of significant tunnel settlement, tensile strain, shear stress or normal stress acting on an existing tunnel. To investigate the influence zone of new tunnel excavation crossing beneath an existing tunnel, a series of three-dimensional centrifuge tests in dry sand was carried out. To identify the zone of substantial stress transfer on an existing tunnel, three-dimensional numerical back-analysis was also conducted using an advanced hypoplasticity constitutive model with small strain stiffness considered. The influence zone of new tunnel excavation on the existing tunnel is presented and discussed.
\end{abstract}

Keywords: crossing tunnel interaction, influence zone, three-dimensional centrifuge modeling, hypoplasticity model

\section{INTRODUCTION}

Due to the growing demand for underground space in densely populated cities, an increasing number of closely spaced tunnels and basements are constructed (Boonyarak and Ng, 2014; Ng et al., 2013a; Ng et al., 2014; Shi et al., 2015). Interaction among tunnel-pilebasement is inevitable. It is reported that the construction of new tunnel excavation caused excessive settlement and cracks on adjacent tunnels (Cooper et al., 2002). In order to prepare for mitigation measure or planning for instrumentation on an existing tunnel, an influence zone of a new tunnel excavation should be identified and investigated.

Morton and King (1979) proposed the influence zone as a shear surface, which rise at an angle of $\beta=$ $45^{\circ}-\phi^{\prime} / 2$ to the vertical plane, from the tunnel springline to the ground surface ( $\phi^{\prime}$ is the friction angle of soil). In addition to the concept of shear surface, the influence zone based on soil-structure interaction was proposed. Based on centrifuge tests of tunneling effects on piles, Jacobsz et al. (2001) proposed critical and normal influence lines which were $60^{\circ}$ and $45^{\circ}$, respectively to the horizontal plane. These influence lines proposed by Jacobsz et al. (2001) were based on settlement of piles. $\mathrm{Ng}$ et al. (2013b) investigated the effects of volume loss and weight loss on crossingtunnel interaction using three dimensional centrifuge test and numerical back-analysis. They reported that large tunnel settlement, tunnel gradient and tensile strain in the tunnel lining was observed. However, the influence zone regarding crossing tunnel interaction was not identified.

The objective of this study is to investigate the influence zone of an advancing new tunnel excavation on an existing tunnel. To identify the influence zone of crossing tunnels, a series of centrifuge test was carried out. Three-dimensional numerical back-analysis using a hypoplasticity constitutive model with small strain stiffness was also conducted.

\section{THREE-DIMENSIONAL CENTRIFUGE MODELING}

\subsection{Typical model setup}

Figure 1a shows a plan view of a typical setup of a centrifuge model package to investigate the influence zone of perpendicularly crossing-tunnel interaction. The outer diameter (D) of the existing and new tunnels is equivalent to $6 \mathrm{~m}$ in prototype scale (at $60 \mathrm{~g}$ ). The tests were conducted in the geotechnical centrifuge located at the Hong Kong University of Science and Technology.

\subsection{Test program}

Two tests, Tests E2N3 and E2N5, are reported in this paper. Figure $1 \mathrm{~b}$ shows elevation view of Test E2N3. The cover depth-to-diameter ratios (C/Ds) of the 
existing and new tunnels were 2 and 3.5, respectively. The pillar depth-to-diameter ratio (P/D) was 0.5 , where pillar depth is the vertical clear distance between tunnels. The cover depth of the existing tunnel, cover depth of the new tunnel and pillar depth were equivalent to $12 \mathrm{~m}, 21 \mathrm{~m}$ and $3 \mathrm{~m}$, respectively. The purpose of this test is to study the effects and influence zone of a new tunnel excavation at a close spacing from the existing tunnel.

Different from Test E2N3, the P/D in Test E2N5 was 2 (see Fig. 1c) given that the $C / D$ of the existing tunnel in both tests was the same $\left(\mathrm{C} / \mathrm{D}_{\text {Existing }}=2\right)$. The objective of this test is to investigate the influence zone of tunnel excavation with different $\mathrm{P} / \mathrm{Ds}$.

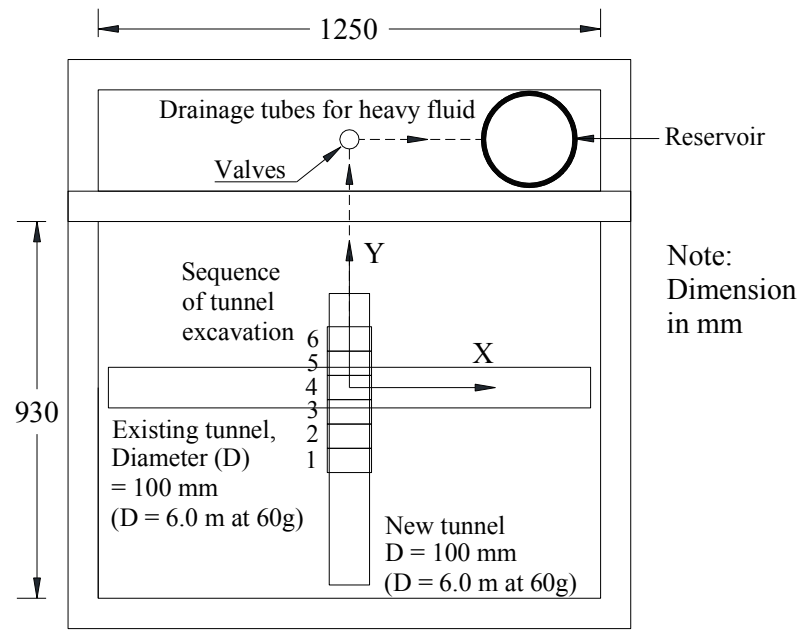

(a)

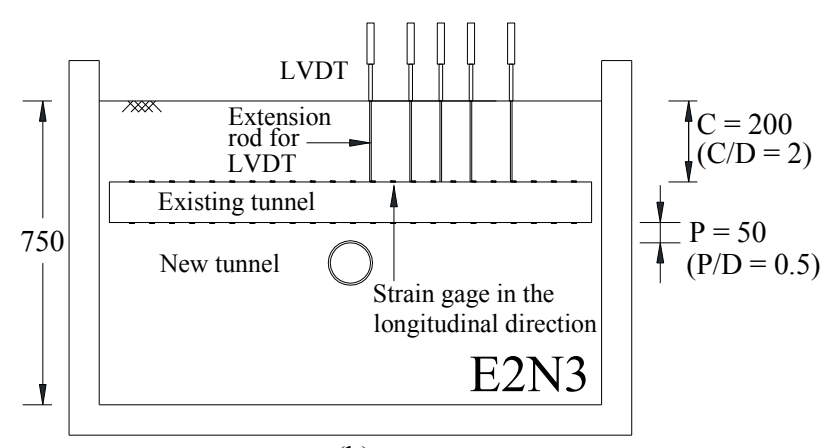

(b)

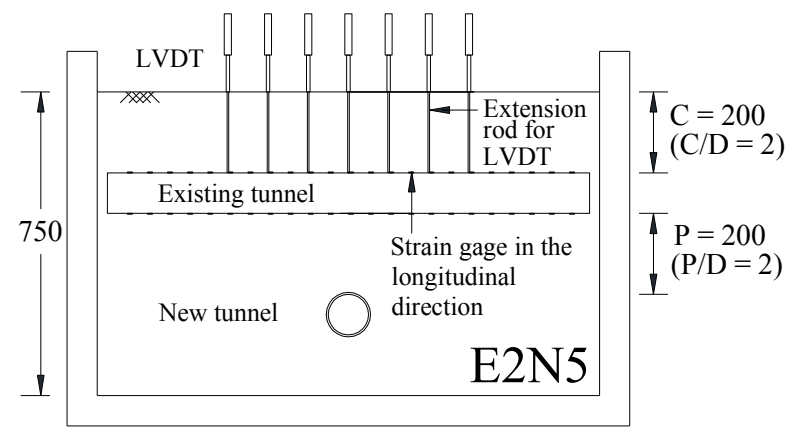

(c)

Fig. 1. (a) Typical plan view of centrifuge model package; elevation view of Tests (b) E2N3; (c) E2N5.

\subsection{Simulation of tunnel excavation in-flight}

Tunnel excavation was simulated in-flight using a novel device "Donut" as shown in Figure 2. In this device, an outer rubber membrane models effects of volume loss, equivalent to $2 \%$. An inner rubber bag simulates effects of weight loss (i.e., soil removal). During model preparation, heavy fluid $\left(\mathrm{ZnCl}_{2}\right)$ is injected into the outer rubber membrane and the inner rubber bag. The heavy fluid has the same density as the sand $\left(1530-1535 \mathrm{~kg} / \mathrm{m}^{3}\right)$ in each test.

To simulate tunnel excavation, heavy fluid inside each "Donut" is drained away using a valve, which can be controlled in-flight. The new tunnel is excavated from stage one to six (refer to Fig. 1a).

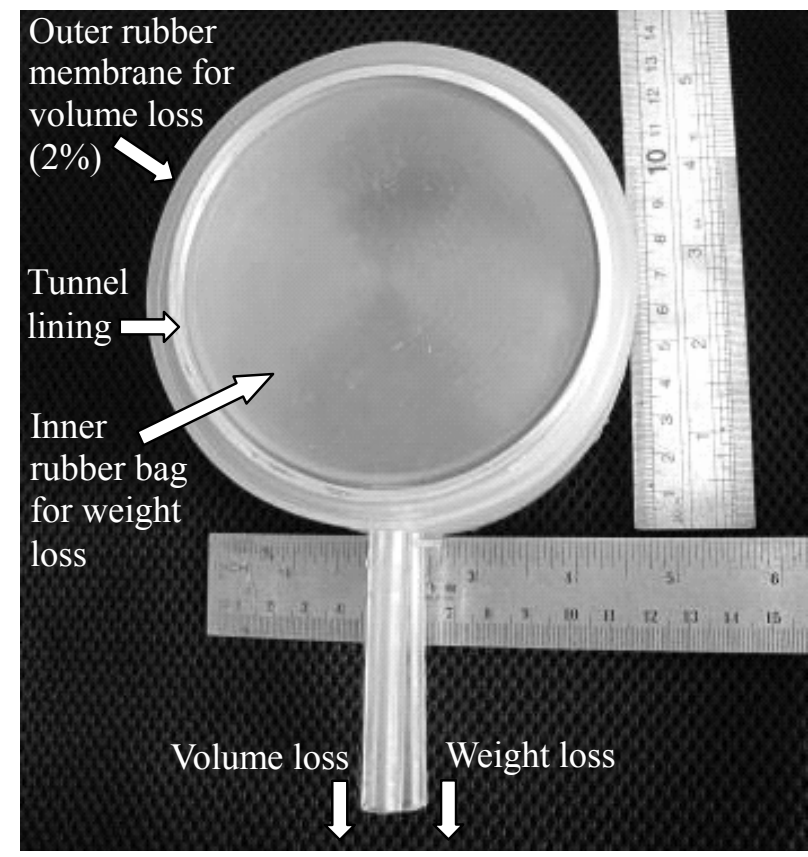

Fig. 2. "Donut" simulating effects of volume and weight losses of tunnel excavation (modified from $\mathrm{Ng}$ et al., 2013b).

\subsection{Instrumentation}

Four types of instruments were installed on the existing tunnel to monitor the tunnel responses due to the excavation of the new tunnel.

As shown in Figure $1 \mathrm{~b}$ and $1 \mathrm{c}$, extension rods were placed along the crown of the existing tunnel to measure tunnel settlement using linear variable differential transformers (LVDTs). Strain gages were attached along the crown and invert of the existing tunnel to measure strain in the longitudinal direction.

At the center of the existing tunnel, eight sets of strain gages were installed at even spacing on the inner and outer surface of the tunnel lining to capture strain in the transverse direction. In addition to strain gage, four potentiometers were used to measure change in tunnel radius. For brevity of the paper, results from strain gages in the transverse direction and potentiometers are not reported.

\subsection{Model preparation and test procedures}

Dry pluviation technique was adopted to prepare 
Toyoura sand in each test. To control the density of soil sample in each test, a drop height of $500 \mathrm{~mm}$ and a delivery rate of about $100 \mathrm{~kg}$ per hour were used. Each tunnel was placed when the pluviated sand reached the desired height. The average relative density of sand in Tests E2N3 and E2N5 were $64 \%$ and $65 \%$, respectively.

After the model preparation, the model box was transfer to the centrifuge platform. The centrifuge was gradually spun up to centripetal acceleration of $60 \mathrm{~g}$. The initial readings were taken at this stage. Then, tunnel excavation was carried out in-flight from stage one to six. Finally, the centrifuge was spun down.

\section{THREE-DIMENSIONAL NUMERICAL BACK-ANALYSIS}

To improve the understanding of stress transfer in the centrifuge test, finite element analysis was carried out three-dimensionally using PLAXIS 3D 2013 (Brinkgreve et al., 2013).

\subsection{Mesh and boundary conditions}

Figure 3 shows the finite element mesh of Test E2N5. The dimension of the mesh and geometry of tunnels were identical to that in the centrifuge test. Due to symmetry, only half of the model was required for the analysis. The soil was simulated using a 10-node tetrahedral element. A six-node elastic plate element was used to model the tunnel lining.

The existing tunnel and the lining of the new tunnel were modeled as "wished-in-place" by activating the lining of both tunnels and deactivating some soil elements inside the tunnel in the initial stage. At the plane of symmetry $(\mathrm{X} / \mathrm{D}=0)$, an additional constraint was adopted for the tunnel lining. At the plane of symmetry, translational movement in the " $\mathrm{X}$ " direction and rotation around the "Y" and " $Z$ " axes of the tunnel lining was not allowed.

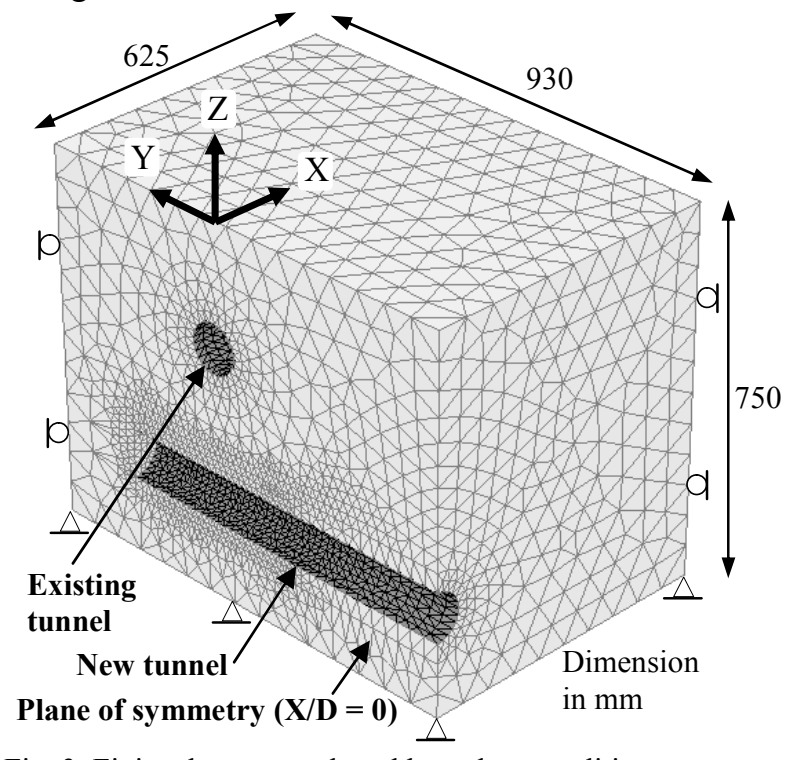

Fig. 3. Finite element mesh and boundary conditions.

\subsection{Constitutive model and model parameters}

Toyoura sand was modeled using hypoplasticity with small strain stiffness (von Wolffersdorff, 1996; Niemunis and Herle, 1997).

Hypoplasticity model requires total 13 parameters. A critical state friction angle $\left(\phi_{c}\right)$ and parameters controlling void ratios $\left(\mathrm{h}_{\mathrm{s}}, \mathrm{n}, \mathrm{e}_{\mathrm{d} 0}, \mathrm{e}_{\mathrm{c} 0}\right.$ and $\left.\mathrm{e}_{\mathrm{i} 0}\right)$ were determined based on the study of Herle and Gudehus (1999). Exponent $\alpha$, exponent $\beta$ and small strain stiffness parameters $\left(\mathrm{m}_{\mathrm{R}}, \mathrm{m}_{\mathrm{T}}, \mathrm{R}, \beta_{\mathrm{r}}\right.$ and $\left.\chi\right)$ were calibrated by curve fitting the triaxial test results with local strain measurement and bender element reported by Yamashita et al. $(2000,2009)$. To initialize the stress conditions, the coefficient of at-rest earth pressure $\left(\mathrm{K}_{0}\right)$ was assumed to be 0.5 . The model parameters are summarized in Table 1.

The tunnel lining was modeled with linear elastic material having a Young's modulus of $69 \mathrm{GPa}$. Density and Poisson's ratio of the tunnel lining were assumed to be $2700 \mathrm{~kg} / \mathrm{m}^{3}$ and 0.33 , respectively.

Table 1. Summary of model parameters adopted for finite element analysis.

\begin{tabular}{ll|ll}
\hline $\begin{array}{l}\text { Parameter controlling soil } \\
\text { behavior in large strain range }\end{array}$ & \multicolumn{2}{l}{$\begin{array}{l}\text { Parameter controlling soil } \\
\text { behavior in small strain range }\end{array}$} \\
\hline$\phi_{\mathrm{c}}$ & $30^{\circ}$ & $\mathrm{m}_{\mathrm{R}}$ & 8.00 \\
$\mathrm{~h}_{\mathrm{s}}$ & $2.6 \mathrm{GPa}$ & $\mathrm{m}_{\mathrm{T}}$ & 4.00 \\
$\mathrm{n}$ & 0.27 & $\mathrm{R}$ & 0.00003 \\
$\mathrm{e}_{\mathrm{d} 0}$ & 0.61 & $\beta_{\mathrm{r}}$ & 0.20 \\
$\mathrm{e}_{\mathrm{c} 0}$ & 0.98 & $\chi$ & 1.00 \\
$\mathrm{e}_{\mathrm{i} 0}$ & 1.10 & & \\
$\alpha$ & 0.50 & & \\
$\beta$ & 3.00 & & \\
\hline
\end{tabular}

\subsection{Numerical back-analysis procedures}

The procedures of numerical modeling basically followed those in the centrifuge test. At the initial stage, stress condition was established in $1 \mathrm{~g}$ conditions with $\mathrm{K}_{0}=0.5$. To simulate rise in centrifugal acceleration, gravity was increased by 60 times $\left(\Sigma \mathrm{M}_{\text {weight }}=60\right)$. After that, tunnel excavation in each stage was carried out by simulating the effects of volume and weight losses. The effects of volume loss, equaling $2 \%$, were simulated by using a "surface contraction", which is one of utilities in PLAXIS. This surface contraction is defined as strain normal to the tunnel lining. The effects of weight loss (i.e., removal of the soil inside the new tunnel) were simulated by deactivating the relevant soil elements.

\section{INTERPRETATION OF RESULTS}

Measured and computed results reported in this paper are in prototype scale unless otherwise stated.

\subsection{Tunnel settlement}

Settlement of the existing tunnel due to the new tunnel excavation underneath at the end of tunnel excavation is shown in Figure 4.

In Test E2N3, the maximum measured tunnel 
settlement was about $0.3 \% \mathrm{D}$ (i.e., $18 \mathrm{~mm}$ ), which exceeds the recommended serviceability limit of 15 $\mathrm{mm}$ (LTA, 2000). The maximum measured tunnel settlement in Test E2N3 (i.e., P/D of 0.5) was about $50 \%$ larger than that in Test E2N5 (i.e., P/D of 2). The larger tunnel settlement in Test E2N3 was mainly due to a larger reduction in vertical stress along the invert of the existing tunnel. Detailed explanations are given later in section 4.4.

As expected, the zone of large tunnel settlement (compared with LTA, 2000) occurred directly above the new tunnel within a distance of $1.5 \mathrm{D}$ from the centerline of the new tunnel in Test E2N3.

There are minor discrepancies between the measured and computed results, but the overall trend of numerical data reasonably captured major aspects of the measured results. These discrepancies may be due to the fact that some model parameters were adopted from the literature and empirical relationships.

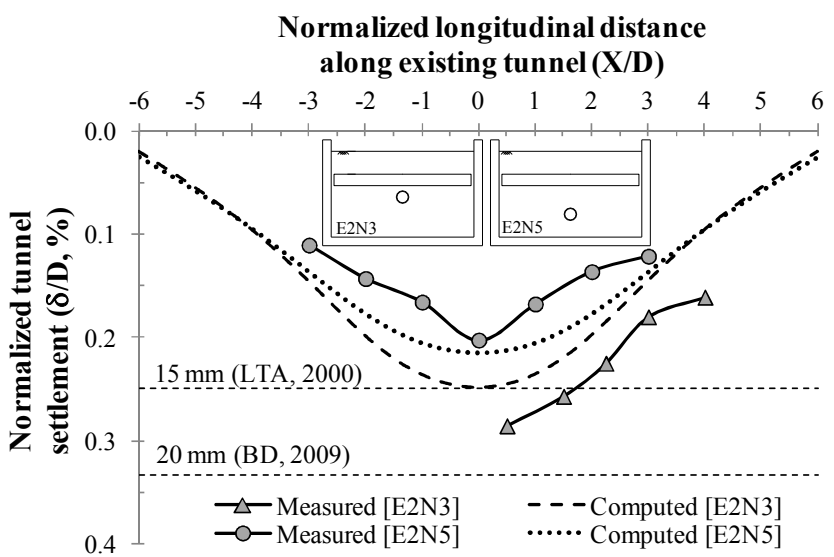

Fig. 4. Settlement of the existing tunnel

\subsection{Induced strain and shear stress in the tunnel}

Figure 5 compares the measured and computed strain induced in the lining along the invert of the existing tunnel at the end of the tunnel advancement. The positive and negative signs denote induced tensile strain and induced compressive strain in the tunnel lining, respectively.

Due to differential settlement of the existing tunnel (refer to Fig. 4), sagging moment was induced directly above the new tunnel. As a result, tensile strain was induced at the invert of the existing tunnel. The measured and computed maximum induced tensile strain of $152 \mu \varepsilon$ and $181 \mu \varepsilon$, respectively, was found in Test E2N3. These strains exceeded the cracking tensile strain of $150 \mu \varepsilon$ for unreinforced concrete (ACI, 2001). The measured and computed maximum induced tensile strains in Test E2N5 are $127 \mu \varepsilon$ and $144 \mu \varepsilon$, respectively. These strains were $16 \%$ (for measured results) and 20\% (for computed results) smaller than that in Test E2N3, where the former test had a larger $\mathrm{P} / \mathrm{D}$ than the latter test.

Shear stress acting on the tunnel lining was deduced by differentiating bending moment, which was converted from induced strain in the tunnel lining. The maximum shear stress in each test and the allowable shear stress of concrete are summarized in Table 2. The allowable shear stress was estimated to be $660 \mathrm{kPa}$ at a given concrete compressive strength $\left(\mathrm{f}_{\mathrm{c}}^{\prime}\right)$ of $50 \mathrm{MPa}$ and a reduction factor of 0.55 (ACI, 2011). The measured and computed maximum deduced shear stress in Tests E2N3 exceeded the allowable limit, suggesting that crack is likely to occur in the tunnel lining.

The location where the induced tensile strain exceeded the cracking tensile strain was from the center of the existing tunnel to an offset distance of $0.5 \mathrm{D}$. In addition, the zone of tensile strain in the tunnel lining extended up to $2.5 \mathrm{D}$ from the center of the existing tunnel. The locations of maximum shear stress in Tests E2N3 and E2N5 were $1.8 \mathrm{D}$ and $2.2 \mathrm{D}$, respectively from the center of the existing tunnel. Considering the extent of tensile strain and location of maximum shear stress, a distance up to $2.5 \mathrm{D}$ from the center of the existing tunnel is where instruments should be installed.

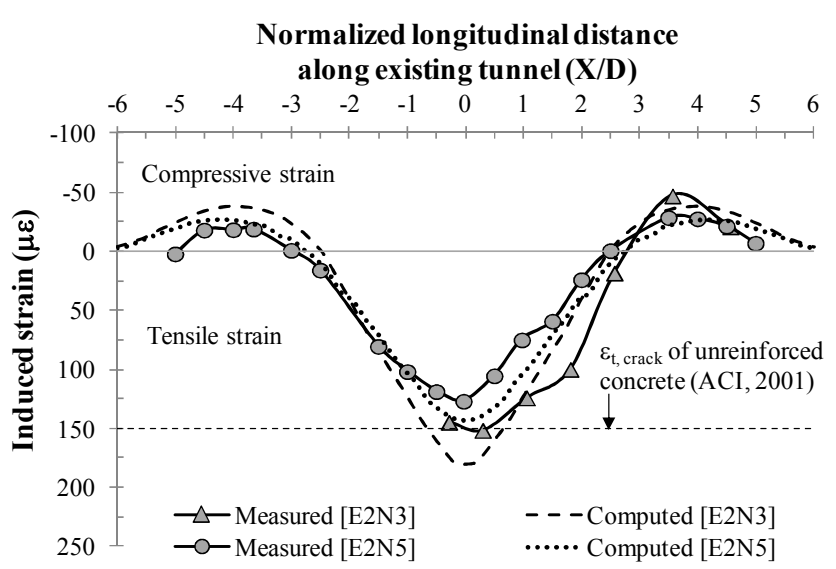

Fig. 5. Comparison of induced strain in the longitudinal direction of the existing tunnel

Table 2. Summary of maximum shear stress in tunnel lining.

\begin{tabular}{|c|c|c|c|}
\hline \multirow{2}{*}{$\begin{array}{l}\text { Test } \\
\text { ID }\end{array}$} & \multicolumn{2}{|c|}{$\begin{array}{l}\text { Maximum shear stress } \\
(\mathrm{kPa}) \text { deduced from }\end{array}$} & \multirow{2}{*}{$\begin{array}{l}\text { Offset distance of } \\
\text { maximum shear stress } \\
\text { from centerline of the } \\
\text { new tunnel }\end{array}$} \\
\hline & $\begin{array}{l}\text { measured } \\
\text { results }\end{array}$ & $\begin{array}{l}\text { computed } \\
\text { results }\end{array}$ & \\
\hline E2N3 & 780 & 690 & $1.8 \mathrm{D}$ \\
\hline E2N5 & 510 & 560 & $2.2 \mathrm{D}$ \\
\hline
\end{tabular}

\subsection{Effects of stress change on the existing tunnel}

Change in vertical effective stress $\left(\Delta \sigma_{v}{ }^{\prime}\right)$ due to tunneling at the end of tunnel excavation is shown in Figure 6 . The change in stress was normalized with the initial vertical effective stress $\left(\Delta \sigma_{v}{ }^{\prime}\right)$ before the tunnel advancement (at 60g).

Contour of normalized vertical stress change in Test E2N3 is shown in Figure 6a. The largest reduction in vertical stress occurs above the crown and below the invert of the new tunnel. This resulted in large settlement and induced tensile stress at the center of the 
existing tunnel (see Figs. 4 and 5). At an offset distance of $1.5 \mathrm{D}$ from the center of the existing tunnel, stress increased below the invert $\left(\Delta \sigma_{\mathrm{v}}{ }^{\prime} / \Delta \sigma_{\mathrm{v}}{ }^{\prime}\right.$ of 0.1$)$. This is because of stress redistribution to maintain stress equilibrium ( $\mathrm{Ng}$ et al., 2013b).

BD (2009) suggested the allowable limits of stress change not more than $20 \mathrm{kPa}$ on tunnel lining. Along the invert of the existing tunnel, the reduction in vertical stress exceeded the allowable limit of $-20 \mathrm{kPa}$ from X/D of 0 to X/D of 1 . These locations correspond to $\Delta \sigma_{\mathrm{v}}{ }^{\prime} / \Delta \sigma_{\mathrm{v}}{ }^{\prime}$ of -0.2 . In addition, at an offset distance more than $1.5 \mathrm{D}$, the vertical stress increased more than $20 \mathrm{kPa}\left(\Delta \sigma_{\mathrm{v}}{ }^{\prime} / \Delta \sigma_{\mathrm{v}}{ }^{\prime}\right.$ of +0.1$)$. This suggests that the structural analysis considering these changes of stress due to tunneling should be taken into account.

Comparing with Morton and King (1979) and Jacobsz et al. (2001), the critical influence zone for stress reduction $(\mathrm{X} / \mathrm{D}<1)$ can be captured. However, their proposed influence zone proposed did not consider the zone of stress increase (at X/D $>1.5$ ) at the invert of the existing tunnel.

Figure $6 \mathrm{~b}$ shows normalized stress change in Test E2N5. The location where stress reduction was larger than $20 \mathrm{kPa}$ was within $1.3 \mathrm{D}$ from the center of the existing tunnel. It also can be seen that the proposed influence zone by Morton and King (1979) and Jacobsz et al. (2001) overestimated the influence zone in this test.

\subsection{Stress transfer in the longitudinal direction of the new tunnel}

Figure 7 shows incremental normal stress acting on the crown, springlines and invert of the existing tunnel at different locations of the advancing tunnel face (Y/D).

In Test E2N3, normal stress increased gradually at the crown as the new tunnel advanced. At both springlines, there was a reduction in normal stress. At the invert, once the new tunnel approached the existing tunnel (i.e., Y/D of -0.3), a slight increase in normal stress was observed. When the new tunnel was directly beneath the existing tunnel (Y/D of 0.3), normal stress dropped sharply. The maximum reduction in normal stress occurred at this stage. As the tunnel advanced further (Y/D from 0.9 to 1.5), there was a slight rebound of stress due to redistribution of stresses.

In case E2N5, there was an increase in normal stress at the crown. At both springlines, the reduction in stress was smaller than that in case E2N3 as the P/D for the latter was smaller. At the invert, normal stress reduced substantially as the new tunnel advanced. The reduction in normal stress at the invert in Test E2N3 was greater than that in Test E2N5, resulting in larger tunnel settlement in the former than the latter (refer to Fig. 4).

By considering the stress change in the two tests, significant stress change occurred when the tunnel face was located within 1D in front of the centerline of the existing tunnel and $1 \mathrm{D}$ beyond (i.e., $\mathrm{Y} / \mathrm{D}= \pm 1$ ).

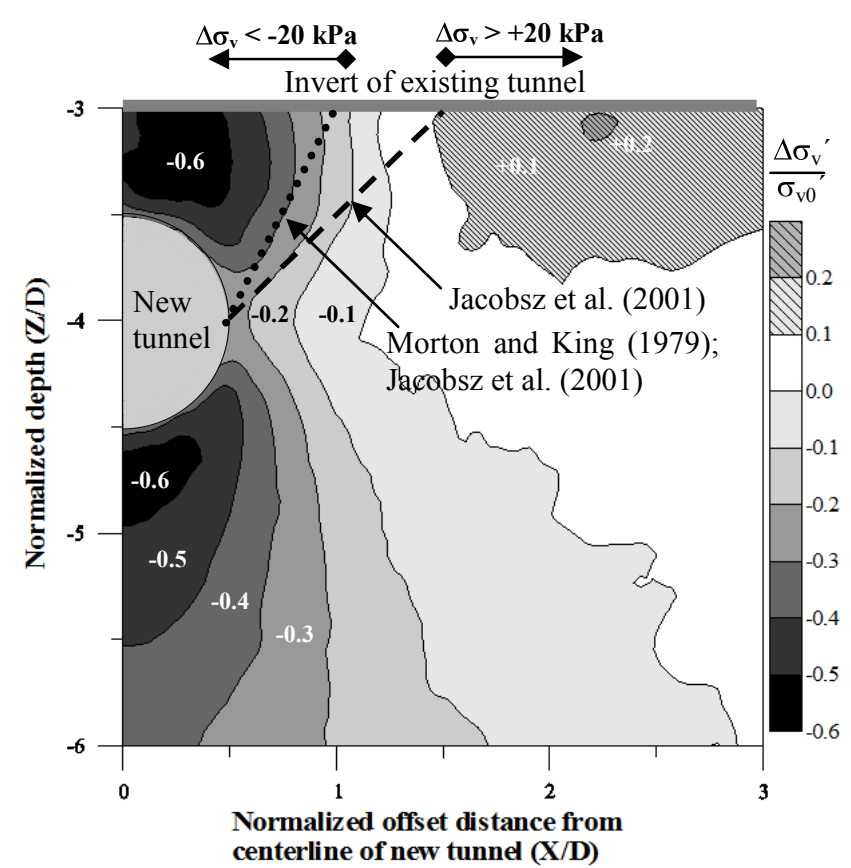

(a)

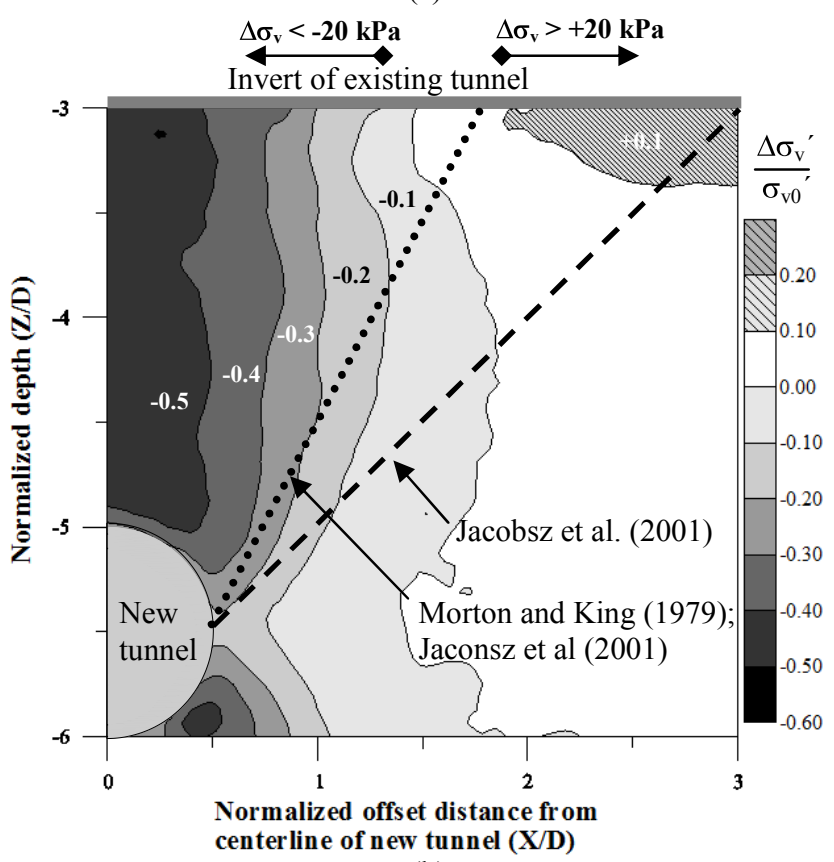

(b)

Fig. 6. Contours of incremental vertical effective stress normalized with initial vertical effective stress before tunnel excavation $\left(\Delta \sigma_{\mathrm{v}}{ }^{\prime} / \sigma_{\mathrm{v} 0}{ }^{\prime}\right)$ in Tests (a) E2N3; (b) E2N5

\section{CONCLUSIONS}

Based on three-dimensional centrifuge modeling and numerical back-analysis, the following conclusions may be drawn:

a) For a given volume loss, a zone of large tunnel settlement (larger than $15 \mathrm{~mm}$ set by LTA, 2000) was from center of the existing tunnel to an offset distance of $1.5 \mathrm{D}$ in the test with $\mathrm{P} / \mathrm{D}$ of 0.5 . When $\mathrm{P} / \mathrm{D}$ increased from 0.5 to 2 , the measured and computed settlement of the existing tunnel was still within the allowable limit. This is because the zone 
of large stress reduction was directly above the new tunnel. The effects of stress reduction on the existing tunnel decreased with increasing $\mathrm{P} / \mathrm{D}$.

b) In the test with $\mathrm{P} / \mathrm{D}$ of 0.5 , the induced tensile strain exceeded the cracking tensile strain (ACI, 2001). Moreover, the computed shear stress was also larger than the allowable shear stress (ACI, 2011).

c) The influence zone considering the location of stress change larger than $20 \mathrm{kPa}(\mathrm{BD}, 2009)$ on the existing tunnel in the test with $\mathrm{P} / \mathrm{D}$ of 0.5 was within $1 \mathrm{D}$ for stress reduction and more than $1.5 \mathrm{D}$ for stress increase. It appears that simplified influence zones proposed in the literature may not be able to capture the influence zone of crossing tunnel interaction.

d) In the longitudinal direction of the new tunnel, the influence zone of tunnel excavation was estimated to be $\pm 1 \mathrm{D}$ from the face of the advancing tunnel. The critical stage of largest stress reduction occurred when the new tunnel was directly underneath the existing tunnel, not at the end of tunnel excavation. This reveals that the conventional two-dimensional plane strain modeling and analysis may not necessarily yield conservative results.

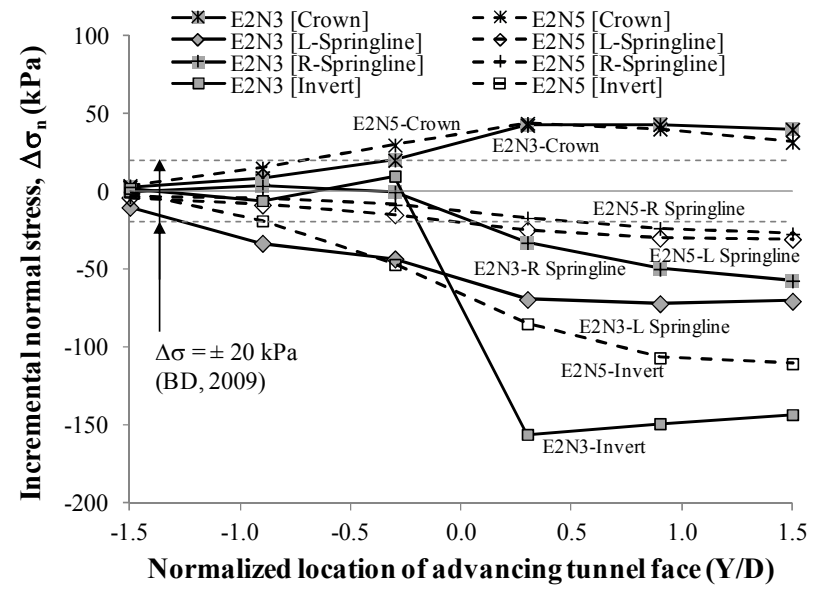

Fig. 7. Incremental normal stress acting on the existing tunnel at different locations of advancing tunnel face

\section{ACKNOWLEDGEMENTS}

The authors would like to acknowledge the financial support provided by the General Research Fund 617410 from the Research Grants Council of the HKSAR.

\section{REFERENCES}

1) American Concrete Institute. (2001): Control of Cracking in Concrete Structures (ACI 224R-01). M.I.

2) American Concrete Institute. (2011): Building Code Requirements for Structural Concrete and Commentary (ACI 318M-11). M.I.

3) Boonyarak, T. and Ng, C. W. W. (2014): Effects of construction sequence and cover depth on crossing-tunnel interaction. Canadian Geotechnical Journal. Accepted and available online on 31 Oct. 2014.

4) Brinkgreve, R. B. J., Engin, E. and Swolfs, W. M. (2013): PLAXIS 3D 2013 User manual. Plaxis bv, Delft.

5) Building Department (BD). (2009): Practice Note for Authorized Persons APP-24. Technical notes for guidance in assessing the effects of civil engineering construction / building development on railway structures and operations. Building department of the government of HKSAR.

6) Cooper, M. L., Chapman, D. N., Rogers, C. D. F. and Chan, A. H. C. (2002): Movements in the Piccadilly Line tunnels due to the Heathrow Express construction. Géotechnique, 52(4), 243-257.

7) Herle, I. and Gudehus, G. (1999): Determination of parameters of a hypoplastic constitutive model from properties of grain assemblies. Mechanics of cohesivefrictional materials, 4, 461-486.

8) Jacobsz, S. W., Standing, J. R., Mair, R. J., Soga, K., Hagiwara, T., Sugiyama, T., (2001): Tunneling effect on driven piles. Proc. of the International Conference on Response of buildings to excavation-induced ground movements. Imperial College, CIRIA, London, 1-15.

9) Land Transport Authority (LTA). (2000): Code of practice for railway protection. Development and Building Control Department, Singapore.

10) Morton, J. D. and King, K. H. (1979): Effects of tunnelling on the bearing capacity and settlement of piled foundations. Proc. Tunnelling' 79, Institute of Mining and Metallurgy, London, 57-68.

11) Ng, C.W.W., Shi, J.W. \& Hong, Y. (2013a): Threedimensional centrifuge modelling of basement excavation effects on an existing tunnel in dry sand. Canadian Geotechnical Journal. Vol. 50, No.8, 874-888.

12) Ng, C. W. W., Boonyarak, T. and Mašín, D. (2013b): Threedimensional centrifuge and numerical modeling of the interaction between perpendicularly crossing tunnels. Canadian Geotechnical Journal, 50(9), 935-946.

13) Ng, C.W.W., Hong, Y., \& Soomro, M.A. (2014): Effects of piggyback twin tunnelling on a pile group: three-dimensional centrifuge and numerical modelling. Géotechnique. Accepted on 17 Sep. 2014.

14) Niemunis, A. and Herle, I. (1997): Hypoplastic model for cohesionless soils with elastic strain range. Mech. of CohesFrict. Mater., 2, 279-299.

15) von Wolffersdorff, P. A. (1996): A hypoplastic relation for granular materials with a predefined limit state surface. Mech. of Cohes.-Frict. Mater., 1, 251-271.

16) Shi, J.W., Ng, C.W.W. \& Chen, Y.H. (2015): Threedimensional numerical parametric study of the influence of basement excavation on existing tunnel. Computers and Geotechnics. Vol. 63, 146-158.

17) Yamashita, S., Jamiolkowski, M. and Lo Presti, D.C.F. (2000): Stiffness nonlinearity of three sands. Journal of Geotechnical and Geoenvironmental Engineering, 126(10), 929-938.

18) Yamashita, S., Kawaguchi, T., Nakata, Y., Mikami, T., Fujiwara, T. and Shibuya, S. (2009): Interpretation of international parallel test on the measurement of $G_{\max }$ using bender elements. Soils and Foundations, 49(4), 631-650. 